\title{
Variable responses of hawkmoths to nectar-depleted plants in two native Petunia axillaris (Solanaceae) populations
}

\author{
Anna Brandenburg • Redouan Bshary
}

Received: 17 September 2010/ Accepted: 10 January 2011/Published online: 26 January 2011

(C) Springer Science+Business Media B.V. 2011

\begin{abstract}
Pollination success of deceptive orchids is affected by the density and distribution of nectar providing plant species and overall plant density. Here we extended the framework of how plant density can affect pollination to examine how it may promote the success of plant intraspecific cheaters. We compared hawkmoth behaviour in two native populations of Petunia axillaris, where we simultaneously offered rewarding and manually depleted $P$. axillaris. We asked whether pollinator foraging strategies change as a function of plant density and whether such changes may differentially affect nectarless plants. We observed the first choice and number of flowers visited by pollinators and found that in the dense population, pollinators visited more flowers on rewarding plants than on nectar-depleted plants. In the sparse population, such discrimination was absent. As we found no differences in nectar volume between plants of the two populations, the observed differences in plant density may be temporal. We reason that if differences were more permanent, an equivalent of the remote habitat hypothesis prevails: in a sparse population, cheating plants benefit from the absence of inter- and intraspecific competitors because pollinators tend to visit all potential resources. In a denser population, a pollinator's optimal foraging strategy involves more
\end{abstract}

Handling Editor: Lars Chittka.
A. Brandenburg
Institute of Plant Science, University of Bern,
Altenbergrain 21, 3013 Bern, Switzerland
A. Brandenburg $(\bowtie) \cdot R$. Bshary
Institute of Biology, University of Neuchâtel,
Emile Argand 13, 2009 Neuchâtel, Switzerland
e-mail: anna.brandenburg@unine.ch

selectivity. This would cause between-plant competition for pollinators in a pollinator-limited context, which applies to most hawkmoth-pollinated systems. We propose that nectar-provisioning of plants can be density-dependant, with cheaters able to persist in low density areas.

Keywords Pollination - Nectar - Density - Mutualism · Cheating $\cdot$ Petunia

\section{Introduction}

Mutualisms are ubiquitous and of great importance in most biological systems (Bronstein 2001). Their stability and persistence is puzzling given that they often involve investments (Bshary and Bronstein 2004; Herre et al. 1999; Pierce et al. 2002; Sachs et al. 2004). Therefore a principal question is which ecological conditions could select for a stable investment or, alternatively, for the breakdown of mutualism.

Plant-pollinator interactions offer an excellent system within which to study the conditions that affect the stability of mutualisms (Bronstein et al. 2006): plants invest in the production of nectar while most pollinators benefit the plants through pollen transfer as a by-product of selfserving foraging behaviour. Nectar production can be physiologically costly for the plant (Brandenburg et al. 2009; Pyke 1991; Southwick 1984). Nevertheless most angiosperms produce a nectar reward for pollinators, while well-studied cases like deceptive orchids are the exception (Duffy and Stout 2008; Gigord et al. 2002, 2004; Internicola et al. 2006; Sun et al. 2010). The persistence of deceptive orchids demonstrates that cheating can be an evolutionarily stable strategy under certain circumstances (Jersakova et al. 2006; Maynard-Smith 1982). 
Understanding why generally there seems to be selection against the reduction of nectar production in plants is fundamental in order to understand how plant-pollinator mutualisms can be maintained over evolutionary time.

A key ecological variable that affects cooperation is population structure both on the species and the community level. Plant populations/communities with higher densities generally attract a larger number of pollinators and have a higher reproductive output than lower densities (Bernhardt et al. 2008; Gunton and Kunin 2009; Kunin 1997). Large floral aggregations supposedly emit more olfactory and visual cues to attract pollinators (Shao et al. 2008). Pollinators prefer foraging in abundant arrays in order to maximize their foraging success (Goulson 1994; Goulson et al. 1998; Heinrich 1979; Kunin 1993; Mitchell et al. 2004). As a consequence of pollinator preferences, plant populations with a low density may suffer from a decrease in pollination visits (pollinator limitation) due to a reduced attractiveness caused by fewer attraction cues, a lower total reward and longer travel times between bouts (Eriksson and Ehrlen 1992; Feldman 2008; Klinkhamer et al. 1989; Sih and Baltus 1987). Very small or isolated populations are exposed to the risk of going extinct due to inbreeding depression caused by mating with closely related individuals or reproductive failure due to ineffective pollination (absence of pollinators) (Allee effect; Allee 1949; Dornier et al. 2008; Forsyth 2003; Groom 1998; Lamont et al. 1993). For a thorough understanding of the stability of mutualism, one has to understand how variation in population/community structure interacts with the occurrence and frequency of nectarless individuals or species.

This issue has predominantly been studied in the plant family Orchidaceae, where as much as one third of the species (ca. 10,000 species) does not provide any reward (Ackerman 1983; Dafni 1984; Nilsson 1980). It has been demonstrated that large aggregations of deceptive orchids are unfavourable for plant fitness; independent of the density of surrounding rewarding species (Gumbert and Kunze 2001; Internicola et al. 2006). However, if growing in a moderate frequency (not outnumbering the rewarding species), the density of rewarding plants can influence the reproductive outcome of deceptive individuals. In this context, two opposing hypotheses have been developed: the magnet species hypothesis and the remote habitat hypothesis. The former predicts that species offering no reward have greater reproductive success in populations where co-flowering nectar-providing species are abundant (magnets) (Johnson et al. 2003; Thomson 1978) and nectarless specimen are visited accidentally (facilitative interaction) (Laverty 1992). In contrast, the remote habitat hypothesis suggests that reproductive success of deceptive orchids is highest in sparse, remote populations in the absence of rewarding co-flowering species that can be used as alternative food sources (Lammi and Kuitunen 1995). In a pollinator-limited context, co-flowering species and a high density of conspecifics promote competition for pollination (Callaway 1995) therefore it might be advantageous to grow in a more remote habitat.

A more general prediction from the remote habitat hypothesis is that plant species that provide a certain percentage of cheaters (individuals with a reduced investment) do better in low densities. According to the remote habitat hypothesis, low plant densities would set the stage for selection on low nectar quantities. From a pollinator's viewpoint, the optimal foraging strategy is to visit plants/ flowers rather indiscriminately when density is low while they should be selective when plant densities are high. This is because under low density conditions the costs for switching between plants/patches is relatively high relative to the costs of visiting flowers with low nectar, while the reverse holds for high density conditions (Zimmerman and Cook 1985). Thus, we need to understand how pollinators behave when faced with cheating plants and in how far their reaction depends on population/community structure.

Several aspects of pollinator foraging strategies were identified that may act as partner control mechanisms by promoting nectar production:

(1) Avoidance of non-rewarding plants (Gilbert et al. 1991)

(2) Short drinking duration (Cresswell 1999)

(3) Attending a reduced number of flowers per visit (Hodges 1995; Mitchell 1993)

(4) Switching to other plant species (Goulson 1999)

It has been demonstrated that the low reproductive success of nectarless orchids is mainly caused by pollination or pollinator limitation, as experienced pollinators either avoid nectarless plants or the overall pollinator availability is low in areas with a high local density of deceptive orchids (Tremblay et al. 2005; Vandewoestijne et al. 2009).

Here, we asked how population density may affect the success of intraspecific cheaters by investigating how pollinators respond to plants where nectar was manually depleted ("no nectar") and to plants with reward ("with nectar"), placed in two populations of different densities. We used two natural populations of Petunia axillaris that during our experiments differed in size, density, and frequency of co-occurring plants that are hawkmoth-pollinated like $P$. axillaris (Ando et al. 2001). We collected two measures of pollinator discriminative behaviour: first choice between "with nectar" and "no nectar" P. axillaris, and the visitation rate. We used the data to assess whether pollinator foraging behaviour is plastic facing different ecological settings (density and plant species composition) or whether the pollinators' strategies are general across 
sites. Furthermore, we quantified nectar production of plants in the two populations to infer whether any differences in pollinator behaviour might be best interpreted as adjustments to current conditions or as adjustments to stable population differences and correspondingly evolved differences in plant strategies.

\section{Materials and methods}

Field site and study species

Field studies were conducted in January/February 2007 in Uruguay in two wild Petunia axillaris populations (Fig. 1): observations were done in the first site near José Ignacio (JI) $\left(34^{\circ} 45.739^{\prime \prime} \mathrm{S} 54^{\circ} 341.153^{\prime \prime} \mathrm{W}\right)$ for 11 nights from $10 / 01 / 2007-21 / 01 / 2007$, the second site was situated near Carmelo (C) $\left(33^{\circ} 56^{\prime} 18.4^{\prime \prime} \mathrm{S} 58^{\circ} 22^{\prime} 13.3^{\prime \prime} \mathrm{W}\right)$ and observations were conducted for 10 nights from 05/02/2007-15/02/ 2007. In Uruguay, P. axillaris habitats are generally open meadows with grasses (Poaceae) intermingled with few shrubs and small trees, also known as the typical Pampa landscape.

In $\mathrm{C}$ we recorded co-flowering species such as Glandularia peruviana, Ipomea purpurea, Passiflora coerulea (and many more) and sphingophilous species such as
Nicotiana longiflora, Macrosiphonia petrea and Oenothera affinis, whereas co-flowering sphingophilous species were absent in JI.

Petunia axillaris generally grows on very dry sandy soil, with a low nutrient availability (A. Robredo, pers. comm.) (C) or a clay-sand mix (JI), and are maximally exposed to sunlight.

Population sizes and number of open flowers were measured prior to experiments by counting the number of all detectable $P$. axillaris plants and their respective flowers at each study site. In $P$. axillaris new flowers usually open during the senescence of the oldest flower. Thus, the fluctuation in number of open flowers on native petunias should have been moderate and thus our initial count a good estimation for the availability during the experiments.

In JI, $P$. axillaris plants grew in a scattered manner along a $5 \mathrm{~km}$ road solely within a $5 \mathrm{~m}$ wide area on each side of the road (total area: $50,000 \mathrm{~m}^{2}$ ). In C, plants grew in a restricted area of $125 \mathrm{~m} \times 60 \mathrm{~m}$ (total area: 7,500 $\mathrm{m}^{2}$ ).

Plant density was determined by the occurrence of all plants/area in $\mathrm{m}^{2}$. The maximal distance between two plants was $120 \mathrm{~m}$ in JI and $30 \mathrm{~m}$ in C, which can easily be bridged by hawkmoths (Moré et al. 2005). The mean distance between a plant and its nearest neighbour was $12 \mathrm{~m}$ in JI. As plants grew along a road, they never appeared in large patches but rather in a long strip. In $\mathrm{C}$, plants
Fig. 1 Geographical map of the two experimental sites in Uruguay. The site Carmelo (C) was characterized by a high Petunia axillaris density, whereas the site José Ignacio (JI) harboured a low P. axillaris population density. The two experimental sites are $200 \mathrm{~km}$ apart. Example pictures show individual $P$. axillaris plants growing in different manners in the two sites (big patches with many flowers in $\mathrm{C}$, single plants with 1-2 flowers along a road in JI)

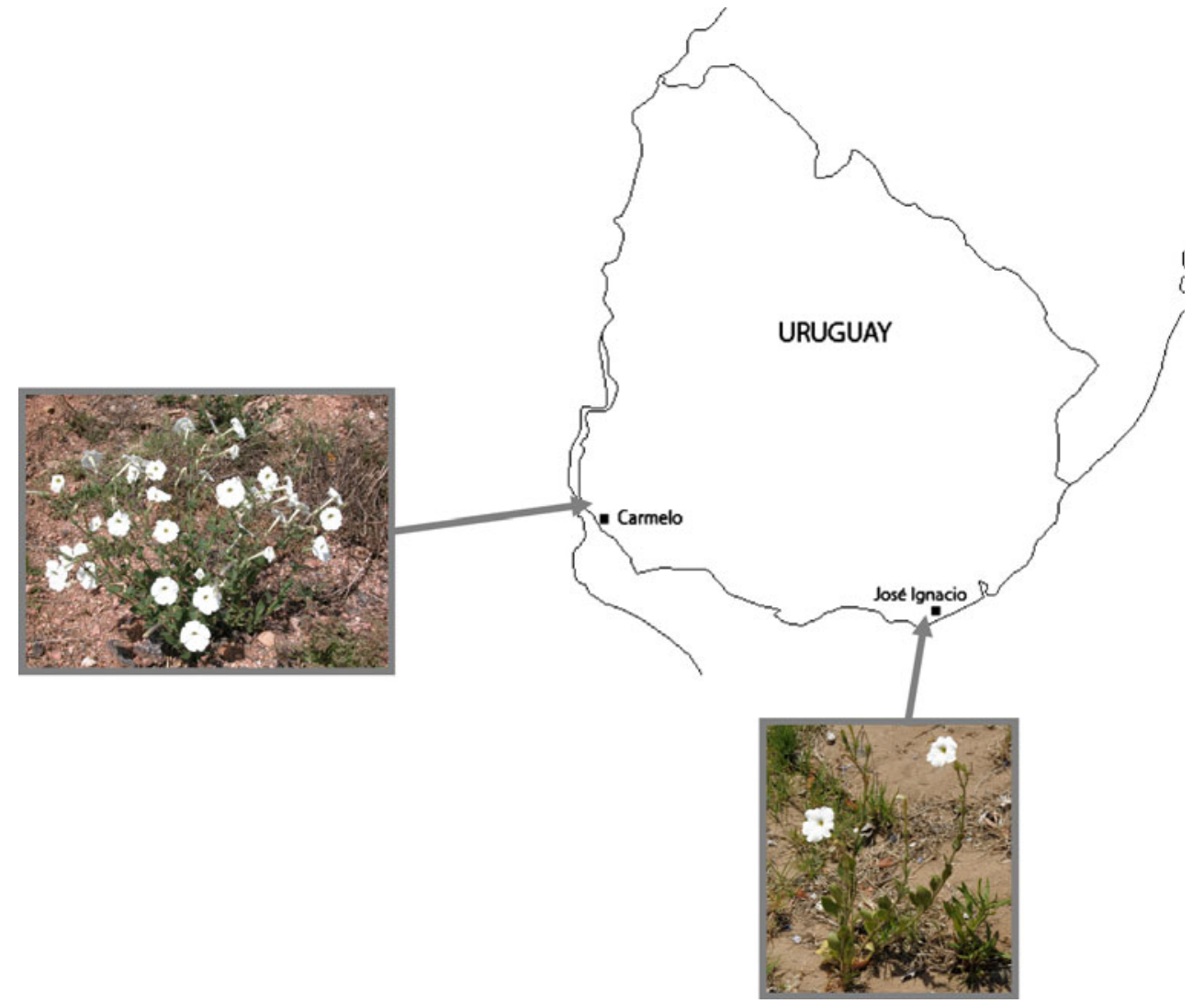


commonly overlapped in their growth, therefore it was hard to determine the mean distance between two separate plants $(<1 \mathrm{~m})$. The prevalent growth habit of petunias in $\mathrm{C}$ was in larger joined patches than in JI. Both sites were surrounded by habitat unsuitable for $P$. axillaris. We therefore assumed that all counted plants in each site belonged to the same gene pool. Our experimental plants were Petunia axillaris $\mathrm{N}$, a self-compatible line from the Botanical Garden of Rostock. These lines are cross-compatible with the wild form and have a similar floral anatomy, characterized by white flowers with long floral tubes and abundant nectar. Plants were grown in plastic pots $(\varnothing 14 \mathrm{~cm})$ under greenhouse conditions (Insituto Nacional de Semillas, Montevideo, Uruguay) before removal to the test sites.

\section{Nectar volume measurements}

We measured nectar volumes both directly in the field and from plants that were grown under standardised conditions in the laboratory. Flowers were cut below the ovaries (at the end of the floral tube) and below the corolla. This piece of floral tube, containing the whole amount of nectar, was transferred immediately to a centrifuge vial $(0.5 \mathrm{ml})$ with pin holes in the bottom and placed in a $1.5 \mathrm{ml}$ centrifuge vial. The small centrifuge vial thus acted as a sieve and nectar was collected in the bottom of the surrounding bigger vial. Centrifugation took place for $30 \mathrm{~s}$ at $7,000 \mathrm{rpm}$. In the field, a portable centrifuge (GmCLab, Gilson) was used, while a tabletop centrifuge (1-15, Sigma) was used in the laboratory. Nectar volume was determined by means of an Eppendorf $10 \mu$ pipette using a graded capillary pipette tip.

In the field, nectar volume measurements for local plants were taken from single flowers of 15 and 12 random plants selected after the final nocturnal observation (ca. $12 \mathrm{pm}$ ) on wild $P$. axillaris in JI and C. In addition we processed six unvisited flowers from our experimental "with nectar" as well as "no nectar" plants.

In the laboratory, plants from both populations were grown in a climate chamber of the University of Bern preceding the field experiments (climate chamber conditions: $16 / 8 \mathrm{~N}: \mathrm{D}, 70 \% \mathrm{rh}) .20$ plants per location were cultivated from seeds collected in the field, derived from various mothers. All laboratory nectar measurements took place $1 \mathrm{~h}$ before extinction of light $(5 \mathrm{pm})$ using flowers of same age. In total, 5 flowers per individual were measured for JI and C (resulting in 100 measurements per site).

Experimental set up and pollinator observation

Experiments were conducted from 20:30 to 00:30, resulting in a total of 84 observation hours for both experimental sites (44 h in JI, $40 \mathrm{~h}$ in C). In between experiments, plants were returned to the housing and covered to prevent any additional interactions with insects. Six plants were arranged in a $3 \times 2 \mathrm{~m}$ array, with 3 "no nectar" and 3 "with nectar" plants alternating in two rows. At each site, the plants were always placed at the same location, within $3 \mathrm{~m}$ of naturally occurring $P$. axillaris that were matched in size, offering between 10 and 30 flowers over the course of the experiment. In our experimental plants, the number of flowers was equal in both "no nectar" and "with nectar" plants but different between nights. The range of open flowers on "with nectar" and "no nectar" experimental plants was $1-8$, the mean number of open flowers per array was $6.7 \pm 1.1$ in $\mathrm{JI}$ and $9.6 \pm 1.6$ in $\mathrm{C}$.

In "no nectar" plants, nectar was extracted by piercing the tube at the bottom with a needle and nectar was collected with a tissue once per hour. The "with nectar" plants were also pierced in the tube to control for wounding but above the nectar level to avoid any loss of nectar. Nectar removal did not cause any detectable differences in scent emission between categories 30 min after nectar extractions in a laboratory analysis using a Proton transfer reaction-mass spectrometer (High sensitivity PTR-MS, Ionicon ${ }^{\circledR}$ ), a detector for continuous quantification of volatile organic compounds. Spatial arrangement of "no nectar" and "with nectar" plants was constant during the entire experiment. After each pollinator visitation, any plant was replaced by a new plant with equal numbers of open flowers to avoid any effects that a plant-pollinator interaction may have on subsequent pollinator behaviour.

The hawkmoths visiting our experimental set-up were not marked, therefore we cannot exclude that the same individuals visited the plants in the same/consecutive nights. To identify species, hawkmoths were captured on our experimental set-up in $\mathrm{C}$ after experiments had finished on the very last day of observations and released after capture. Hawkmoth species observed as floral visitors of P. axillaris included Manduca diffisa, Manduca sexta, Eumorpha vitis, Eumorpha labruscae, Agrius cingulata and Eryinnyis ello. We did not capture any moths in JI, but observed M. sexta and A. cingulata foraging on P. axillaris in JI. There was never more than a single hawkmoth visiting our experimental set-up. We have no information on individual experiences of the moths but it appears to be likely that moths had visited other $P$. axillaris plants before and that they hence were not naive.

Data collection and analysis

The differences in nectar volumes were analyzed using a Mann-Whitney-U test for two independent samples.

The visits by moths were directly observed by one experimenter who dictated the observations to another experimenter. We noted which of the six plants was visited 
first, how many plants were visited in total, and the number of flowers visited on each plant. The attempt to record drinking time per flower failed. Due to poor visibility it was impossible to be sure when the proboscis precisely entered and left a flower while the high speed at which hawkmoths fed on each flower $(<1 \mathrm{~s})$ would have demanded such precision.

For the analyses we only considered a pollinator's first visit to a plant if repeated visits occurred. We calculated one value per moth for the parameters of interest to conduct matched pair analyses (Wilcoxon signed rank test for two related samples) for plants with or without nectar the mean number of plants visited, the mean number of flowers visited, and the mean number of flowers per plant visited (which excludes moths that only visited one type of plants). In addition, we ran a $\chi^{2}$ test on first choice. We used SPSS ${ }^{\circledR}$ and VassarStats.

\section{Results}

Petunia axillaris population size and density at both sites

At Jose Ignacio (low density) the population comprised 235 plants with 252 open flowers yielding densities of 0.0047 plants $/ \mathrm{m}^{2}$ and 0.005 flowers $/ \mathrm{m}^{2}$. There were no other coflowering sphingophilous species in the habitat. At C (high density), the population consisted of 78 plants with 140 open flowers, yielding densities of 0.01 plants $/ \mathrm{m}^{2}$ and 0.02 flowers $/ \mathrm{m}^{2}$, two and four times the densities seen in the low density site respectively (Fig. 1). In addition to $P$. axillaris, the following nectar-providing, sphingophilous species were co-flowering: Oenothera sp., Nicotiana longiflora, Macrosiphonia longiflora and Datura stramonium, adding to the reward density at this site.

\section{Nectar volume measurements}

Our experimental manipulation of nectar volumes appeared to be successful as flowers of the "with nectar" category had a mean nectar volume of $7.25( \pm 2.52) \mu$ l while we could not detect any nectar in the "no nectar" category (0 $\mu \mathrm{l})$ (Mann-Whitney- $U$-Test, $\mathrm{m}=\mathrm{n}=6, \mathrm{Z}=-3.08$, $P=0.002)$.

Nectar volume of 14 randomly chosen wild $P$. axillaris flowers in JI was on average 5.1 $( \pm 3.2) \mu \mathrm{l}$ per single flower. One of the flowers was completely empty. In C, 4 of the 12 measured flowers were empty. The average nectar volume per flower including the empty flowers was $2.5( \pm 3.06) \mu$ l. The difference in nectar volume between the two sites was not significant (Mann-Whitney- $U$-Test, $\mathrm{m}=14, \mathrm{n}=12$, $\mathrm{Z}=-1.902, P=0.059$ ).
Nectar volume measurements conducted under controlled conditions in the climate chamber resulted in a mean nectar volume of $21.06( \pm 4.59) \mu l$ per flower for P.axillaris from the $\mathrm{C}$ population and $19.87( \pm 5.23)$ per flower for the JI population (Mann-Whitney- $U$-Test, $\mathrm{m}=\mathrm{n}=100, \mathrm{Z}=-0.77, P=0.45)$.

\section{Pollinator behaviour}

A total of 33 hawkmoths were observed, 16 in the high density site (C) and 17 in the low density site (JI). Hawkmoths at $\mathrm{C}$ preferentially approached plants with nectar first (13 with, 3 no; $\chi^{2}=5.06, \mathrm{~N}=16, d f=1$, $P=0.02)$ while no such significant differences were found at JI ( 8 with, 9 no; $\chi^{2}=0, \mathrm{~N}=17, d f=1, P=1$ ).

There was no significant difference in number of plants visited between the two categories "with" and "no nectar" at either site (1. C: mean number of plants visited per moth in the category with nectar: $1.8 \pm 0.8$; no nectar: $1.7 \pm 0.9$, Wilcoxon signed rank tests, initial $\mathrm{N}=16,6$ ties, resulting $\mathrm{N}=10, \mathrm{Z}=-1.165, P=0.244$, Fig. $2 ; 2$. JI: mean number of plants visited per moth in the category with nectar: $1.86 \pm 0.86$, no nectar: $1.64 \pm 0.75$, Wilcoxon signed rank test, initial $\mathrm{N}=17,5$ ties, resulting $\mathrm{N}=12, \mathrm{Z}=-1.155, P=0.248$, Fig. 2).

To allow for a matched pair comparison of $\mathrm{N}$ flowers visited we only used moths that had visited both "with nectar" and "no nectar" plants. At the high density site (C), pollinators visited significantly more flowers with nectar (mean number of flowers visited per moth in the category with nectar: $3.1 \pm 2.1$, no nectar $1.7 \pm 0.9$, Wilcoxon signed rank test, initial $\mathrm{N}=9,2$ ties, resulting $\mathrm{N}=7, \mathrm{Z}=-1.98, P=0.047$, Fig. 3 ), while no such significant differences were found at the low density site (JI) (mean number of flowers visited per moth in the category with nectar: $2.64 \pm 1.65$, no nectar: $2.21 \pm 1.12$, Wilcoxon signed rank test, initial $\mathrm{N}=14,5$ ties, resulting $\mathrm{N}=9, \mathrm{Z}=-0.84, P=0.4$, Fig. 3).

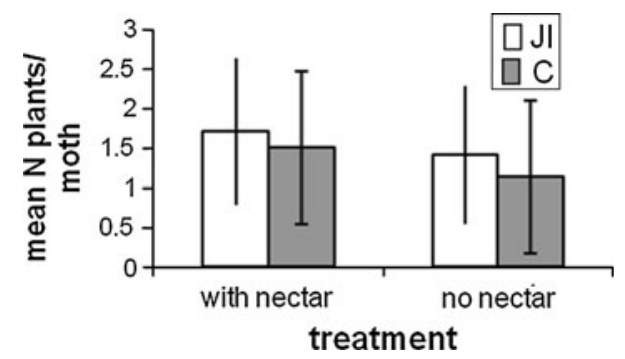

Fig. 2 Average number of plants visited per hawkmoth in the two categories "with" and "no nectar" at two native P. axillaris sites differing in plant density (high density site: C, low density site: JI). There is no significant difference between categories at either site $(\mathrm{C}: P=0.24 ; \mathrm{JI}: P=0.25$ ) 


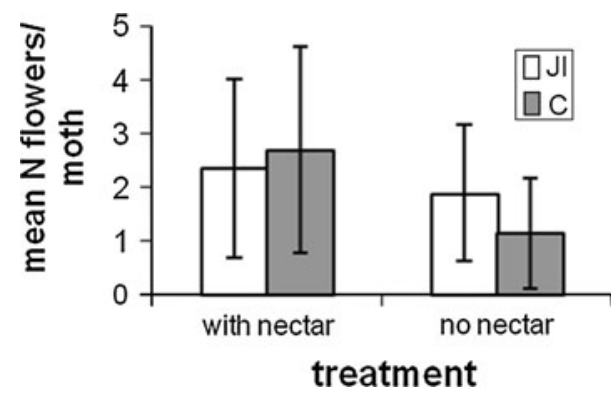

Fig. 3 Average number of flowers visited per hawkmoth in the two categories "with" and "no nectar" at two native P. axillaris sites differing in plant density (high density site: $\mathrm{C}$, low density site: JI). The difference in $\mathrm{N}$ flowers visited is significant in $\mathrm{C}(P=0.047)$, but not in JI $(P=0.4)$

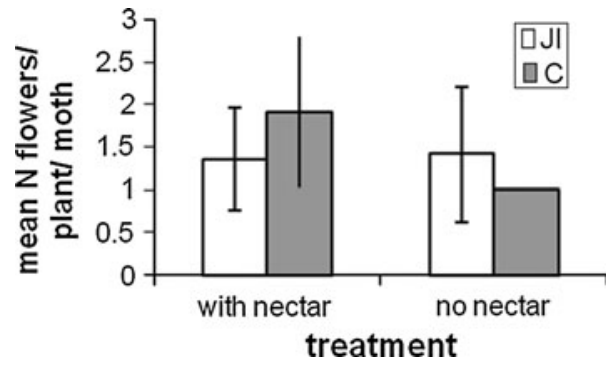

Fig. 4 Average number of flowers per plant visited per hawkmoth in the two categories "with" and "no nectar" at two native $P$. axillaris sites differing in plant density (high density site: $\mathrm{C}$, low density site: $\mathrm{JI})$. The difference in $\mathrm{N}$ flowers per plant visited is significant in $\mathrm{C}$ $(P=0.027)$ but not in JI $(P=0.752)$

Both results persisted when we calculated the number of flowers per plant visited (C: mean number of flowers per plant visited per moth in the category with nectar: $1.8 \pm 1.04$, no nectar: $1 \pm 0$, Wilcoxon signed rank test, initial $\mathrm{N}=9,3$ ties, resulting $\mathrm{N}=6, \quad \mathrm{Z}=-2.2$, $P=0.027$, Fig. 4; JI: number of flowers per plant visited per moth in the category with nectar: $1.4 \pm 0.63$, no nectar: $1.44 \pm 0.82$, Wilcoxon signed rank test, initial $\mathrm{N}=14,8$ ties, resulting $\mathrm{N}=6, \mathrm{Z}=-0.315, P=0.752$, Fig. 4).

\section{Discussion}

Our results suggest that there is no standardised "decision rule" of pollinator behaviour facing cheating and rewarding Petunia axillaris. The differences between sites appear to be robust if one considers that our lack of knowledge regarding several parameters (pollinator species composition, age, sex, experience of individuals) introduced potential variance in our data that would favour the null hypothesis that no differences exist. While the majority of studies have observed that the density of flowering species can be positively correlated with pollinator visitation rates and plant reproductive success (Gunton and Kunin 2009; Kunin 1993, 1997; Sih and Baltus 1987; Sun et al. 2010), so far no one has explicitly focussed on the phenotypic plasticity of pollinator foraging behaviour facing cheaters derived from a rewarding species in dense and sparse populations.

Our results show that pollinator visitation rates differ in response to the presence/absence of nectar between sites (Figs. 3, 4). Furthermore, our findings are in line with the general predictions of the remote habitat hypothesis which states that cheating plants profit from growing in remote habitats with low densities (Lammi and Kuitunen 1995). Originally developed for deceptive orchids, we were able to convert the findings of Lammi and Kuitunen to a system where cheating is normally absent. The remote habitat hypothesis incorporates assumptions from both optimal foraging theory (Pyke 1984) and biological market theory (Johnstone and Bshary 2008; Noe and Hammerstein 1995), which both predict that pollinators should become less discriminative when plant densities are low. This is because choice options and total nectar abundance are lower and distances between food sources increase so that the optimal foraging strategy becomes to inspect any potential resource.

Several studies on deceptive orchids have demonstrated that these species do best in low densities with few allospecific competitors (Internicola et al. 2006; Lammi and Kuitunen 1995). Our data suggest that the implications of the remote habitat hypothesis are much broader and may also apply to nectar-providing species; the equal visitation of rewarding and nectarless plants at low densities indicates a condition that may allow for the selection of reduction in nectar production. In contrast, a competitive situation, such as the high density site, would lead to a decreased fitness of cheating individuals due to fewer pollinator visits and subsequently improper pollen transfer to conspecifics and ultimately severe fitness costs (Duffy and Stout 2008; Flanagan et al. 2009; Kandori et al. 2009), a possible consequence of lower visitation frequencies in our study.

Furthermore, we found that pollinator behaviour in the two populations differed with respect to their first choice: in the high $P$. axillaris density population, pollinators showed a significant preference for "with nectar" plants, whereas in the low density population, there was no such preference. This result was unexpected as it is commonly assumed that pollinators lack the ability to assess nectar contents before probing (Thakar et al. 2003). Deceptive orchids exploit this inability by luring naive pollinators to their flowers, whereas with increasing experience, pollinators learn to avoid nectarless orchid species (Ackerman et al. 1997). With respect to our study we note that pollinators subsequently visited more 'no nectar' plants and hence did not show an overall preference for plants that 
contained nectar. Thus, our results do not provide unambiguous evidence for prior discrimination abilities in hawkmoths.

\section{Ultimate versus proximate scenarios}

A shortcoming of our field experiment is that we have no information neither on individual experiences of pollinators or on plant densities in previous years. The lack of difference in nectar volumes produced by plants from the two sites could be interpreted in two ways. First, if the differences in densities were persistent it could be that associated lower pollinator densities at the low density plant site lead to increased competition over access to pollinators (Feldman 2008; Kunin 1993; Sih and Baltus 1987), which counters the selection on reduced nectar volumes. Second, it could be that the differences in plant densities between sites were only temporary, in which case no differential selection on nectar volumes is to be expected. Similarly, it remains an open question whether the differences in pollinator decision rules between the two sites reflect evolutionary adaptations to local conditions or individual adjustments to current conditions. In any case, it has been demonstrated that learning is of major importance for pollinators to construct an internal representation of the foraging environment, including reward density and distribution. Both working and long term memory are required to establish expectations of average rewards in a patch or population (Chittka and Thomson 2001). The working memory is responsible for memorising the suite of flowers visited (to avoid revisiting) and the long term memory is essential to determine mean rewards (Chittka and Raine 2006; Menzel 1999). It is possible that in low densities, the carry-over effects of the working memory might be less pronounced than in higher densities, so that non-rewarding plants are less quickly abandoned in patches where overall reward availability is lower than in populations were floral (and thus reward) density is higher.

\section{Conclusions}

We document that pollinators' responses to "no nectar" plants differ between two populations. Furthermore, our results add preliminary support to the hypothesis that the density and composition of plant communities have major effects on the exact payoffs in plant-pollinator interactions as these variables seem to affect payoffs of members belonging to the same plant species. Future studies will focus on manipulating plant densities in a single habitat to determine whether this alters pollinator behaviour in line with the predictions of the remote habitat hypothesis and biological market theory. Furthermore, long term data on population densities would allow identifying populations that differ consistently in density in order to test the prediction that low densities select for a reduction in nectar volume. Alternatively, between-year variation in densities within a population could be used to evaluate whether density affects selection on reduced or increased nectar volumes. In addition to that, we are aiming at conducting experiments with near isogenic petunia lines that naturally contain a decreased nectar volume in order to be able to measure precisely how pollinator behaviour influences the fitness of plants with a reduced nectar offering.

Acknowledgments We thank all colleagues for helpful discussions, in particular Cris Kuhlemeier, Mark van Kleunen and Siobhan Braybrook for carefully reading the manuscript, Arturo Rebollo from INASE for growing our plants, Ana Pinto and Matthias Borer for help in the field, and the Swiss National Science Foundation (NCCR "plant survival") for financial support. We also thank two anonymous reviewers and Lars Chittka for their suggestions to improve the manuscript.

\section{References}

Ackerman JD (1983) On the evidence for a primitively epiphytic habit in orchids. Syst Bot 8:474-477

Ackerman JD, Melendez-Ackerman EJ, Salguero-Faria J (1997) Variation in pollinator abundance and selection of fragrance phenotypes in an epiphytic orchid. Am J Bot 10:1383-1390

Allee WC (1949) Group survival value for Philodina roseola, a rotifer. Ecology 30:395-397

Ando $\mathrm{T}$ et al (2001) Reproductive isolation in a native population of Petunia sensu Jussieu (Solanaceae). Ann Bot 88:403-413

Bernhardt CE, Mitchell RJ, Michaels HJ (2008) Effects of population size and density on pollinator visitation, pollinator behavior, and pollen tube abundance in Lupinus perennis. Int J Plant Sci 169:944-953

Brandenburg A, Dell'Olivo A, Bshary R, Kuhlemeier C (2009) The sweetest thing: advances in nectar research. Curr Opin Plant Biol 12:486-490

Bronstein JL (2001) The costs of mutualism. Am Zool 41:825-839

Bronstein JL, Alarcon R, Geber M (2006) The evolution of plantinsect mutualisms. New Phytol 172:412-428

Bshary R, Bronstein J (2004) Game structures in mutualistic interactions: what can the evidence tell us about the kind of models we need? Adv Study Behav 34:59-101

Callaway RM (1995) Positive interactions among plants. Bot Rev 61:306-349

Chittka L, Raine N (2006) Recognition of flowers by pollinators. Curr Op Plant Biol 9:428-435

Chittka L, Thomson JD (2001) Cognitive ecology of pollination. Cambridge University Press, Cambridge

Cresswell JE (1999) The influence of nectar and pollen availability on pollen transfer by individual flowers of oil-seed rape (Brassica napus) when pollinated by bumblebees (Bombus lapidarius). J Ecol 87:670-677

Dafni A (1984) Mimicry and deception in pollination. Ann Rev Ecol Syst 15:259-278

Dornier A, Munoz F, Cheptou PO (2008) Allee effect and selffertilization in hermaphrodites: reproductive assurance in a structured metapopulation. Evolution 62:2558-2569 
Duffy KJ, Stout JC (2008) The effects of plant density and nectar reward on bee visitation to the endangered orchid Spiranthes romanzoffiana. Acta Oecologica Int J Ecol 34:131-138

Eriksson O, Ehrlen J (1992) Seed and microsite limitation of recruitment in plant populations. Oecologia 91:360-364

Feldman TS (2008) The plot thickens: does low density affect visitation and reproductive success in a perennial herb, and are these effects altered in the presence of a co-flowering species? Oecologia 156:807-817

Flanagan RJ, Mitchell RJ, Knutowski D, Karron JD (2009) Interspecific pollinator movements reduce pollen deposition and seed production in Mimulus ringens (Phrymaceae). Am J Bot 96:809-815

Forsyth SA (2003) Density-dependent seed set in the Haleakala silversword: evidence for an Allee effect. Oecologia 136:551-557

Gigord LDB, Macnair MR, Stritesky M, Smithson A (2002) The potential for floral mimicry in rewardless orchids: an experimental study. Proc Roy Soc B 269:1389-1395

Gigord LDB, Macnair MR, Smithson A (2004) Negative frequencydependent selection maintains a dramatic flower color polymorphism in the rewardless orchid Dactylorhiza sambucina (L.) Soo (vol 98, p 6253, 2001). Proc Natl Acad Sci 101:7839-7839

Gilbert FS, Haines N, Dickson K (1991) Empty flowers. Funct Ecol 5:29-39

Goulson D (1994) A model to predict the influence of insect flower constancy on interspecific competition between insect-pollinated plants. J Theor Biol 168:309-314

Goulson D (1999) Foraging strategies of insects for gathering nectar and pollen, and implications for plant ecology and evolution. Perspect Plant Ecol Evol Syst 2:185-209

Goulson D, Stout JC, Hawson SA, Allen JA (1998) Floral display size in comfrey, Symphytum officinale L. (Boraginaceae): relationships with visitation by three bumblebee species and subsequent seed set. Oecologia 113:502-508

Gumbert A, Kunze J (2001) Colour similarity to rewarding model plants affects pollination in a food deceptive orchid, Orchis boryi. Biol J Linn Soc 72:419-433

Gunton RM, Kunin WE (2009) Density-dependence at multiple scales in experimental and natural plant populations. J Ecol 97:567-580

Heinrich B (1979) Resource heterogeneity and patterns of movement in foraging bumblebees. Oecologia 40:235-245

Herre EA, Knowlton N, Mueller UG, Rehner SA (1999) The evolution of mutualisms: exploring the paths between conflict and cooperation. Trends Ecol Evol 14:49-53

Hodges SA (1995) The influence of nectar production on hawkmoth behavior, self-pollination, and seed production in Mirabilis multiflora (Nyctaginaceae). Am J Bot 82:197-204

Internicola AI, Juillet N, Smithson A, Gigord LDB (2006) Experimental investigation of the effect of spatial aggregation on reproductive success in a rewardless orchid. Oecologia 150:435-441

Jersakova J, Johnson SD, Kindlmann P (2006) Mechanisms and evolution of deceptive pollination in orchids. Biol Rev 81:219-235

Johnson SD, Peter CI, Nilsson LA, Agren J (2003) Pollination success in a deceptive orchid is enhanced by co-occurring rewarding magnet plants. Ecology 84:2919-2927

Johnstone RA, Bshary R (2008) Mutualism, market effects and partner control. J Evol Biol 21:879-888

Kandori I, Hirao T, Matsunaga S, Kurosaki T (2009) An invasive dandelion unilaterally reduces the reproduction of a native congener through competition for pollination. Oecologia 159: 559-569

Klinkhamer PGL, Dejong TJ, Debruyn GJ (1989) Plant size and pollinator visitation in Cynoglossum officinale. Oikos 54:201204
Kunin WE (1993) Sex and the single mustard-population density and pollinator behavior effects on seed set. Ecology 74:21452160

Kunin WE (1997) Population size and density effects in pollination: pollinator foraging and plant reproductive success in experimental arrays of Brassica kaber. J Ecol 85:225-234

Lammi A, Kuitunen M (1995) Deceptive pollination of Dactylorhiza incarnate-an experimental test of the magnet species hypothesis. Oecologia 101:500-503

Lamont BB, Klinkhamer PGL, Witkowski ETF (1993) Population fragmentation may reduce fertility to zero in Banksia goodii-a demonstration of the Allee effect. Oecologia 94:446-450

Laverty TM (1992) Plant interactions for pollinator visits: a test of the magnet species effect. Oecologia 89:502-508

Maynard-Smith J (1982) Evolution and the theory of games. Cambridge University Press, Cambridge

Menzel R (1999) Memory dynamics in the honeybee. J Comp Physiol A $185: 323-340$

Mitchell RJ (1993) Adaptive significance of Ipomopsis aggregata nectar production-observation and experiment in the field. Evolution 47:25-35

Mitchell RJ, Karron JD, Holmquist KG, Bell JM (2004) The influence of Mimulus ringens floral display size on pollinator visitation patterns. Funct Ecol 18:116-124

Moré M, Kitching IJ, Cocucci AA (2005) Sphingidae: Esfingidos de Argentina. Hawkmoths of Argentina, L.O.L.A., Buenos Aires

Nilsson LA (1980) The pollination biology of Dactyloriza sambucina (Orchidaceae). Botaniske Notiser 133:367-385

Noe R, Hammerstein P (1995) Biological markets. Trends Ecol Evol 10:336-339

Pierce NE et al (2002) The ecology and evolution of ant association in the Lycaenidae (Lepidoptera). Ann Rev Entomol 47:733-771

Pyke GH (1984) Optimal foraging theory-a critical review. Ann Rev Ecol Syst 15:523-575

Pyke GH (1991) What does it cost a plant to produce floral nectar? Nature 350:58-59

Sachs JL, Mueller UG, Wilcox TP, Bull JJ (2004) The evolution of cooperation. Quart Rev Biol 79:135-160

Shao JW, Zhang XP, Zhang ZX, Zhu GP (2008) Identification of effective pollinators of Primula merrilliana and effects of flower density and population size on pollination efficiency. J Syst Evol 46:537-544

Sih A, Baltus MS (1987) Patch size, pollinator behavior, and pollinator limitation in catnip. Ecology 68:1679-1690

Southwick EE (1984) Photosynthate allocation to floral nectar-a neglected energy investment. Ecology 65:1775-1779

Sun HQ, Alexandersson R, Ge S (2010) Positive effects of flower abundance and synchronous flowering on pollination success, and pollinia dispersal in rewardless Changnienia amoena (Orchidaceae). Biol J Linn Soc 99:477-488

Thakar JD, Kunte K, Chauhan AK, Watve AV, Watve MG (2003) Nectarless flowers: ecological correlates and evolutionary stability. Oecologia 136:565-570

Thomson JD (1978) Effect of stand composition on insect visitation in two-species mixtures of Hieracium. Am Midl Nat 100:431-440

Tremblay RL, Ackerman JD, Zimmerman JK, Calvo RN (2005) Variation in sexual reproduction in orchids and its evolutionary consequences: a spasmodic journey to diversification. Biol J Linn Soc 84:1-54

Vandewoestijne S, Rois AS, Caperta A, Baguette M, Tyteca D (2009) Effects of individual and population parameters on reproductive success in three sexually deceptive orchid species. Plant Biol 11:454-463

Zimmerman M, Cook S (1985) Pollinator foraging, experimental nectar-robbing and plant fitness in Impatiens capensis. Am Midl Nat 113:848-891 